features a specially-designed website that provides videos, text information and learning evaluations in both English and selected local languages. The website's programme has the capacity to generate unified identification codes for the site's visitors based on a registry system linked to his/her email address, facebook account or twitter. After viewing the videos or reading the texts, a short quiz is provided with "successful reach" defined as getting four out of six questions correctly.

Within the initial launch of the website, inputs and feedback were gathered from local partners and end-users through email exchanges.

The early implementation of the online BCC outreach is effective in reaching local MSM and TG populations that are often difficult to reach using offline outreach. Initial observations include;

1. The online videos are sometimes difficult to access due to limited internet bandwidth;

2. Users are reluctant to log in since registration by email or by social media account is needed

3. Concerns about the accent of the video voice-overs as well as the appropriateness of images used in the videos.

Recommendations by end-users include 1. Providing localised websites for better access, 2. Uploading the videos in youtube to allow access without registration; 3. Creation of a promotional video; 4. Coming up with electronic raffles and other rewards to promote access.

The ISEAN Hivos Program's BCC online intervention for HIVAIDS targeting MSM and TGs in South East Asia showed initial positive results. Areas for improvement were identified which will guide the site's continuous re-development. This experience provides lessons on how effective HIV-AIDS-related messages can spread en-masse to otherwise "hidden" but "most-at-risk populations" at a regional Asian context, by the use of ICT.

\section{P5.044 A PROACTIVE APPROACH TO ONLINE CHLAMYDIA SCREENING: QUALITATIVE EXPLORATION OF YOUNG MEN'S PERSPECTIVES OF THE BARRIERS AND FACILITATORS}

doi:10.1136/sextrans-2013-051184.1088

'L M McDaid, ${ }^{2} \mathrm{~K}$ Lorimer. 'Medical Research Council, Glasgow, UK; ${ }^{2}$ Glasgow Caledonian University, Glasgow, UK

Background Increasing access to sexually transmitted infection (STI) testing among young, heterosexual men is advocated as a means of reducing STI rates in the UK. New mobile, social media platforms, such as 'smart-phones', give unprecedented mobile access to the Internet, and the proliferation of Internet forums and social networking sites offer potential mediums for sexual health promotion. Here, we assess the acceptability and potential barriers and facilitators of these for STI testing among young men in Scotland.

Methods Qualitative study including 15 focus group discussions with 60 heterosexual young men (aged 16-24 years) across central Scotland to explore an online approach to proactive screening for Chlamydia trachomatis. Transcripts from audio recordings were analysed with Framework Analysis.

Results Participants were favourable of an online approach for accessing postal Chlamydia tests, even if they felt it was not suitable for them. However, some spoke more favourably of attending specialist sexual health clinics for testing, particularly those from areas of higher deprivation, of younger age, and who had previously attended such clinics. We found differing levels of exposure to and practises of (particularly mobile) Internet use by deprivation and age. Despite reporting Internet access, younger men (aged 16-19 years) largely used mobile/cell phones to place and receive calls and to send SMS text messages and they reported fears over the costs, risks of 'smart-phones' being stolen or broken, and a general disinterest due to a perceived lack of fit with their identities. Conversely, Facebook use was universal.

Conclusion Increasing mobile access to the Internet provides opportunities for re-evaluating how we deliver sexual health promotion and engage young men in STI testing and screening. However, our study suggests that such an approach could potentially widen inequalities by age and socio-economic background and future interventions using such technology should consider how best to counter this.

\section{P5.045 THE FAMILY IN THE HEALTH-DISEASE PROCESS IN AGING WITH HIV/AIDS}

doi:10.1136/sextrans-2013-051184.1089

M Ferreira Lima Neta, E Peters Kahhale. The Pontifical Catholic University of São Paulo (PUC-SP), São Paulo, Brazil

Thirty-two years ago society knew of a new sexually-transmitted disease spread by a human immunodeficiency virus, which causes alterations in a person's life as well as in the lives of family members aware of the seropositivity. With the increase in the number of elderly seropositives, this study aims to analyse their family life starting from the disclosure of $\mathrm{HIV}^{+}$diagnosis. Both the extended and the nuclear families were considered. The research was held at the Clinic of Infectious and Parasitic Diseases of the Federal University of São Paulo - SP. 24 men and 13 women participated - ranging from 60 to 82 years of age. All patients signed the consent forms, answered questions about family relations, self-care, health, illness background and treatment adherence, having submitted two genograms - family of origin and current one -, specifying relatives aware of their HIV status and also informing whom they live with and the status of their relationship. The results show that the established family relationships as well as the style and behaviour of each family member are responsible for the choice of diagnosis disclosure of the HIV infection: three elderly seropositive participants live isolated from their family; for 26 families, this knowledge is restricted to some members, forming a nucleus of trust within the extended family; in eight families, all members know about the seniors living with HIV. Finally, it is clear that family life with HIV seropositivity can affect dynamics both positively and negatively. The positive changes refer to a greater extent of love and care, whereas the negative ones are related to absenteeism and discrimination. Health care is mostly carried out independently, with no family interference, and includes practises of no smoking and no drinking, eating properly and a good treatment adherence; nevertheless, few people practise physical activities.

\section{P5.046 HEALTH AND RELIGION: CANDOMBLE PLACES OF WORSHIP (TERREIROS) AS SPACES FOR PROMOTING HEALTH AND STD/AIDS PREVENTION}

doi:10.1136/sextrans-2013-051184.1090

'D B Oliveira Neto, 'B G Barbosa, 'N Lima, ${ }^{2} \mathrm{~J} M$ da Silva, 'M Siqueira, ${ }^{2} \mathrm{~V} M$ da Silva, ${ }^{2} \mathrm{M}$ A C Guimarães, 'I Brito, ' ${ }^{1} \mathrm{C}$ Cassimiro, 'E Zita. ${ }^{1}$ Ministry of Health - Bureau of Health Surveillance - Department of STD/AIDS and Viral Hepatitis, Brasilia, Brazil; ${ }^{2}$ Rede Nacional de Religião Afro e Saúde, Rio de Janeiro, Brazil

Background Demand for producing video materials for Afro-Brazilian religious communities on STD/AIDS prevention actions. For centuries, Afro-Brazilian religious temples have been spaces for inclusion, welcoming hospitality and counselling for historically excluded groups. The ancestry, ritual practises and interpersonal relationships that are constructed in these spaces make possible affective exchange and the production of knowledge, health promotion and disease prevention.

Methods Bibliographic Search. A technical meeting with the organisers of the National Afro-Brazilian Religion and Health 
Network, literature research, workshops and interviews for the recording of a documentary video.

\section{Results}

- Four workshops carried out in 4 Brazilian states.

- 4,000 initial copies made of a video to showing that candomble religion is a field of knowledge that can offer productive ideas concerning the promotion of health, cultural resistance and development of public health policies.

- Campaigns coordinated with the terreiros for reducing stigmatisation and discrimination, promoting the right to healthcare and civil rights, and improving the quality of life of those living with HIV/AIDS.

Conclusion The importance of STD/AIDS prevention, not only through government policies but also by taking into consideration the knowledge, teachings and care provided in the "terreiros", and by recognising their contribution to the physical, psychological and spiritual health of the participants, based on talks by "the people of the saint" (povo de santo) religious leaders, and their songs, myths and proverbs, all contributing to the promotion of health and STD/ AIDS prevention.

\section{P5.047 HIV/AIDS PREVENTION IN THE SLUMS OF DELHI, INDIA: TARGETED INTERVENTIONS}

doi:10.1136/sextrans-2013-051184.1091

\section{S Bajaj. Cygnus Medicare, New Delhi, India}

India has been at the centre stage of global economic growth in the recent years. It has made an impact in urban India with visible signs; however, vast parts of metropolitan India still remain underdeveloped and impoverished. Large numbers of people live in difficult conditions and are deprived of basic healthcare in many urban quarters, especially the western suburbs of Delhi, which have large slum areas. These slums have a high percentage of migrant workers with low levels of awareness on HIV/AIDS. Although the HIV prevalence is low, yet in terms of individuals infected, the slums are home to a very large and rapidly growing number of people living with HIV.

Cygnus Medicare, a newly emerging healthcare organisation dedicated to providing world class healthcare in resource-limited settings, has been working in Delhi and Haryana for last several years with a strong public health approach. It runs seven fully equipped hospitals where poor people are treated at subsidised rates and special programmes are held which focus on education of high risk groups, including commercial sex workers and migrant workers on HIV. STD Clinics are held on Sundays, benefitting over 12000 people in last 3 years. A large number of awareness camps and activities are organised. The entire medical team periodically goes through trainings and orientations focusing on education and prevention of HIV/AIDS.

The organisation also has an outreach component of service delivery, through which remote slum areas are regularly visited by mobile medical vans to provide curative, diagnostic and educational services to the community.

The response and acceptance to the programme so far has been very positive. Over the last three years, there has been a large increase in the number of people attending the clinics and camps.

\section{P5.048 REACHING WOMEN THROUGH THE INTEGRATION OF HIV TESTING INTO PUBLIC SERVICE SITES: EXPERIENCES FROM THE DEPARTMENT OF MOTOR VEHICLES AND INCOME MAINTENANCE CENTER IN WASHINGTON, DC}

doi:10.1136/sextrans-2013-051184.1092

A Fulwood-Wood, F Hamilton, S Brockington, L George. Family and Medical Counseling Service, Inc., Washington, DC, United States

Background Washington DC has an estimated HIV prevalence rate of $2.2 \%$ and only $50 \%$ may be aware of their infection. Using large volume public service venues may promote HIV testing and directly increase access to HIV testing, thereby increasing the number of residents who know their HIV status. Family and Medical Counseling Service, Inc. (FMCS) implemented a novel programme to provide HIV testing at the Department of Motor Vehicles (DMV) which provides driver's licence and automobile tag services to over 150,000 residents annually. In 2011, we replicated this programme model in the Income Maintenance Center (IMC), the government office that provides residents with public benefits including financial assistance and health insurance.

Methods Dedicated project staff discusses the importance of HIV testing and offer the test to everyone awaiting DMV and IMC services. HIV testing is conducted in private offices inside the DMV and IMC, and all who test positive are immediately referred to care. We present data describing the HIV testing outcomes from the programme.

Results From October 2010 to October 2012, 247,055 individuals were offered an HIV test, 23,111 (9\%) accepted, 21,283 (93\%) were tested, and $113(0.5 \%)$ were positive. The majority of those tested were women $14,667(69 \%)$ between the ages of $23-40(5,463$ or $37 \%)$. Of those tested, $33 \%(7,023)$ were first time testers. Women accounted for $54 \%(3,792)$ of all first time testers.

Conclusions Conducting HIV testing in high volume non-clinical settings, such as the DMV and IMC, is a feasible strategy to engage women in HIV counselling and testing services, including those who have never tested before. Expansion of this programme model to similar public service sites may be necessary to increase access to HIV testing services, encourage routine screening and increase the percentage of individuals in the general population who know their HIV status.

\section{P5.049 CREATING ONLINE COMMUNITIES OF PRACTISE TO SUPPORT UPTAKE AND SUSTAINABILITY OF EVIDENCE- BASED HIV/STI PREVENTION PROGRAMMES}

doi:10.1136/sextrans-2013-051184.1093

L O'Donnell, A Hernandez-Chavez, A Myint-U, D McLean Leow. Education Development Center, Waltham, MA, United States

Background Online communities of practise have the potential to address multiple barriers to the broader dissemination and maintenance of evidence-based HIV/STI interventions. Addressing these barriers is critical to narrowing the gap between what researchers have identified as best practises and what gets delivered in communities to curb the spread of disease. Yet there are few models grounded in implementation science that are useful for guiding the development of online communities that can support high-impact HIV/STI prevention.

Methods The APPLES dissemination model is used to identify goals and specific objectives of an online community of practise; this integrated theoretical model focuses on achieving adoption/ adaptation; priority population identification and penetration; longevity; evaluability, and sustainability. A case example is used to discuss how the APPLES model can guide development of an international online community of practise.

Results Drawing on the APPLES model, key components of an online community to promote high-impact condom distribution were identified. These include: (1) Knowledge and skills-building to address specific APPLES goals and objectives, such as identification and outreach to the highest-risk, highest-impact population segments; (2) Knowledge-sharing and network engagement to identify implementation solutions over the life course of intervention delivery; and (3) Online expert coaching and technical assistance. Components are matched to multimedia activities that encourage both individual learning and community engagement. Challenges to marketing and maintenance are also considered in the development 